\title{
Sleep disturbance in mental health problems and neurodegenerative disease
}

\author{
This article was published in the following Dove Press journal: \\ Nature and Science of Sleep \\ 30 May 2013 \\ Number of times this article has been viewed
}

\author{
Kirstie N Anderson' \\ Andrew J Bradley ${ }^{2,3}$ \\ 'Department of Neurology, \\ Newcastle Upon Tyne Hospitals NHS \\ Trust, Newcastle Upon Tyne, UK; \\ ${ }^{2}$ Eli Lilly and Company Limited, Lilly \\ House, Basingstoke, UK; ${ }^{3}$ Institute \\ of Neuroscience, Newcastle \\ University, Newcastle Upon Tyne, UK
}

\begin{abstract}
Sleep has been described as being of the brain, by the brain, and for the brain. This fundamental neurobiological behavior is controlled by homeostatic and circadian (24-hour) processes and is vital for normal brain function. This review will outline the normal sleep-wake cycle, the changes that occur during aging, and the specific patterns of sleep disturbance that occur in association with both mental health disorders and neurodegenerative disorders. The role of primary sleep disorders such as insomnia, obstructive sleep apnea, and REM sleep behavior disorder as potential causes or risk factors for particular mental health or neurodegenerative problems will also be discussed.
\end{abstract}

Keywords: sleep, mental health, neurodegenerative disorders, cognition

\section{Normal sleep physiology}

Sleep is precisely defined by behavioral and electrophysiological measures. Electrophysiologically, sleep is distinguished from wake by distinct changes in the electroencephalogram (EEG), electrooculography, and muscle activity as measured by electromyography. Based on these measures, sleep has been divided into two states, rapid eye movement (REM) and non-REM (NREM) sleep. There are slow rolling movements on electrooculography during NREM sleep and rapid eye movements during REM sleep. REM sleep is characterized by higher-frequency EEG activity and an almost total loss of skeletal muscle tone seen on the electromyography. ${ }^{1}$ NREM sleep accounts for $75 \%-80 \%$ of total sleep time, predominates during the early stages of sleep, and is subdivided into three stages: N1 (drowsiness), N2 (light sleep), and N3 (deep sleep). ${ }^{2}$ The transition from wake to deep sleep through these stages is accompanied by a slowing of the EEG from high-frequency, low-voltage waves (beta waves) to low-frequency, higher-voltage (1-3 Hz) waves (delta waves), also called slow-wave activity, reflecting an increased cortical synchronicity. ${ }^{1}$ NREM sleep rapidly transitions into REM sleep 60-90 minutes or more after onset. During REM sleep, the EEG shows higher frequency lower amplitude waves in the theta range. ${ }^{1}$ There is regular transition between NREM and REM sleep in approximately 90-120 minute cycles with NREM sleep dominating during the early part of the night and REM later on. The timing and duration of sleep is controlled by two processes: ${ }^{3}$ the homeostatic sleep drive (process $\mathrm{S}$ ), which increases for each hour of wakefulness, and the circadian rhythm (process C), where, naturally, humans sleep during the night and are awake during the day.

This sleep rhythm is driven by the central circadian pacemaker or master clock located in the suprachiasmatic nucleus $(\mathrm{SCN})$ of the anterior hypothalamus.
Correspondence: Kirstie N Anderson Department of Neurology, Royal

Victoria Infirmary, Queen Victoria Road, Newcastle Upon Tyne, NEI 4 LP,

United Kingdom

Tel +44 191 2336161

Email kirstie.anderson@nuth.nhs.uk 
At the cellular level, the master clock is controlled by an array of clock genes ${ }^{4}$ that ensure it runs at a period of just over 24 hours. ${ }^{5}$ The clocks are entrained to the 24-hour cycle by both environmental and endogenous cues called zeitgebers. Light is the major environmental zeitgeber facilitated by photosensitive retinal ganglion cells which have a direct neuronal link from the retina to the SCN via the retinohypothalamic tract. ${ }^{6}$

\section{The role of sleep in mental health and cognition}

Important clues about the role of normal sleep in both memory function and mental health are derived from studies of sleep deprivation (SD) and sleep restriction (SR) in healthy subjects.

In healthy subjects, experimentally induced sleep loss is associated with impairments in a broad range of cognitive functions ${ }^{7,8}$ and people with primary sleep disorders such as insomnia ${ }^{9}$ and sleep apnea ${ }^{10}$ also suffer from cognitive impairments. Cognitive performance also follows a well characterized circadian rhythm, ${ }^{11}$ and people suffering from circadian rhythm disorders also suffer from impairments in cognitive performance. ${ }^{12}$

Both SD, involving complete loss of sleep over several days, and SR, involving partial sleep loss, have been used in experimental studies to examine the effects of sleep loss on cognitive function. During studies of SD and SR, a multitude of cognitive tests have been performed examining a broad range of cognitive domains. Several meta analyses have been performed on the data from studies examining the effects of SD and cognition in healthy subjects. ${ }^{8,13-15}$ There are significantly fewer studies examining the effects of SR on cognition and no meta analyses performed to date.

To summarize the data from a large number of studies examining different aspects of attention, vigilance, and learning tasks under conditions of SD/SR, SD and SR consistently and significantly impair simple attention as evidenced by slowing of reaction time (RT) and increased lapses during simple vigilance tests. The effects of moderate SR accumulate substantially over time and can be equal to the effects of several days of total SD.

Performance within individuals demonstrates increasing variability over increasing time of $\mathrm{SD}$, which is best explained by wake/sleep state instability and the interaction with circadian rhythm during sleep and wake. There is considerable variability between individuals with respect to their susceptibility to the effects of SD and SR, although the mechanisms are as yet unknown. Executive functions are less susceptible to the effects of SD and SR than simple attention and deficits are found less consistently in studies. Logic and rule-based tasks measuring crystallized abilities are not substantially affected by SD. In contrast, tasks involving more divergent and innovative thinking are significantly impaired by SD.

Sleep appears to be necessary for both memory encoding and consolidation and therefore learning and memory are significantly affected by SD both before and after learning. Emotional memory is also susceptible to the effects of SD, which may lead to relative preservation of negative compared to positive and neutral memories.

\section{Sleep disturbance in mental health problems Primary sleep disorders as causal factors in mental health disorders}

Insomnia is the most common primary sleep disorder and is defined as difficulty falling asleep, staying asleep, or nonrestorative sleep despite adequate opportunity to sleep. Within population-based studies, these symptoms alone affect approximately $30 \%$ of adults. ${ }^{16}$ When one adds associated daytime impairment or distress as a function of the insomnia and symptoms lasting over 1 month that are not secondary to another sleep disorder or mental disorder, then prevalence estimates range from $6 \%-10 \% .{ }^{17-20}$ The place of insomnia within both the International Classification for Sleep Disorders and the Diagnostic and Statistical Manual of Mental Disorders highlights the interface between disturbed sleep and the psychological distress associated with that sleep disturbance. ${ }^{21,22}$ Primary insomnia, unrelated to another medical or psychiatric condition, is considered to be part of a psychophysiological hyperarousal process. Age and sex are the best established risk factors, with increased prevalence in women and older adults. However, comorbid medical conditions, ${ }^{23}$ psychiatric illness, ${ }^{24}$ and working night shifts or rotating shifts all represent independent risk factors for insomnia. These conditions are thought to be insomnia precipitants in those already predisposed to developing sleep disturbance. The most common comorbidities associated with insomnia are psychiatric disorders, and it is estimated that $40 \%$ of all insomnia sufferers have a coexisting psychiatric condition. ${ }^{24,25}$ Among these psychiatric disorders, depression is most common, and insomnia is a diagnostic symptom for depressive and anxiety disorders. ${ }^{26}$ Insomnia is increasingly recognized as an independent risk factor for both dysthymia and major depressive disorder. A number of studies, including longitudinal studies in the young and 
elderly ${ }^{27-30}$ and a subsequent meta-analysis, ${ }^{31}$ have shown that those with insomnia are at least twice as likely to develop depression compared to people with no sleep difficulty over the subsequent 1-3 years of follow-up. Those with insomnia comorbid with depression are more likely to remain depressed despite standard treatments; ${ }^{32}$ therefore, depression and anxiety may be consequences of as well as risk factors for disrupted sleep. In particular, the hypervigilance and increased arousal associated with both anxiety and insomnia often lead to bidirectionally intertwined disorders that interfere with both sleep onset and sleep maintenance. ${ }^{33}$ This highlights a potentially underused treatment for depression. There is robust evidence base for cognitive behavioral therapy for insomnia, with many prospective controlled trials showing sustained benefit whether insomnia is primary ${ }^{34,35}$ or comorbid with other medical ${ }^{36,37}$ or psychiatric ${ }^{38-40}$ conditions. Importantly, a number of these studies in patients with associated depression and anxiety show an effect regardless of baseline depression levels and moderate treatment effects on both anxiety and depression outcomes as well as insomnia scores.

\section{Obstructive sleep apnea (OSA)}

Snoring and associated pauses in breathing (but not snoring alone) was strongly associated with major depression in a large US population study. ${ }^{41}$ Depression and neurocognitive symptoms have been associated with OSA but the pathophysiology remains poorly understood and some but not all studies identify OSA as independently associated with depression when other variables are controlled for. ${ }^{42}$ Many of the symptoms of OSA, such as fatigue, low energy, daytime sleepiness, poor concentration, and neurocognitive impairment, overlap with those of depression and may lead to diagnostic difficulty. Improvement of many of these symptoms, including depression measures and quality of life, can be demonstrated with continuous positive airway pressure treatment $t^{43,44}$ making it important to consider OSA as a potential diagnosis or modifiable factor in those with mental health problems.

\section{Schizophrenia}

Disturbed sleep is found in $30 \%-80 \%$ of patients with schizophrenia, depending on the degree of psychotic symptomatology. ${ }^{45,46}$ Sleep disturbance is inversely correlated with quality of life, ${ }^{47}$ and a large number of polysomnographic studies have shown increased sleep latency, reduced sleep consolidation, reduced total sleep time, and increased wake time after sleep onset. The sleep disturbances appear to be an important part of the pathophysiology of schizophrenia.
These effects have been consistently reported in drug-naïve patients, those who have withdrawn from medication, and those being treated with antipsychotics and other psychotropic medication. ${ }^{48,49}$

Analysis of EEG and in particular dream sleep in schizophrenia patients has been of interest to psychiatrists as far back as 1955, when Dement first described a reduction in dream recall in patients with schizophrenia and abnormal REM parameters. ${ }^{50}$ Further studies have shown reduced REM sleep latency, higher REM densities, and a failure of REM rebound after sleep deprivation. ${ }^{51-53}$ However, there are several contradictory results in these studies, and REM sleep variables are not consistently affected.

A number of sleep parameters, such as the amount of slow-wave sleep (SWS) and REM latency, are significantly correlated with clinical variables, including severity of illness, positive symptoms, negative symptoms, outcome, neurocognitive impairment, and brain structure..$^{52,54-56}$ Reduced SWS has been reported in patients with schizophrenia in a number of studies; ${ }^{52,57,58}$ however, there have been contradictory results in patients who were off medication or had never been treated. ${ }^{45}$ More detailed analyses of the spectral composition of the EEG have revealed a consistent and significant reduction of the higher-amplitude and lowerfrequency delta waves, especially in the anterior frontal areas. ${ }^{56}$ Significant negative correlations have been reported between reduced SWS or high-amplitude, low-frequency delta waves and both negative symptoms and neurocognitive impairment. ${ }^{59}$ Given the need for SWS in the consolidation of memory, this offers a potential cause or contributory factor for the neurocognitive impairment in schizophrenia.

In schizophrenia patients, memory consolidation has been shown to be impaired compared to controls and to be positively correlated with the amount of SWS and sleep efficiency. ${ }^{60}$ Manoach et $\mathrm{al}^{61}$ measured the effects of sleep on procedural memory consolidation in schizophrenia patients. Daytime practice improved performance on a finger tapping motor sequence task equally in schizophrenia patients and controls whereas an improvement following overnight sleep was only found in the control group. In a subsequent study, consolidation in schizophrenia patients was dependent on both SWS and stage two sleep in the last quarter of the night. ${ }^{62}$ Therefore, the sleep abnormalities present in schizophrenia may interfere with normal sleep-dependent memory consolidation and therefore have an influence on cognitive function.

The direct effect of antipsychotic medication is unclear, and the confounding effect of neuroleptics is a major problem 
with many studies. First-generation or typical antipsychotics are associated with increased total sleep time, increased sleep continuity, and increased REM latency but the reported effects on other sleep stages are variable. ${ }^{63}$ Treatment withdrawal is followed by a change in sleep structure, mainly in the opposite direction, with a deterioration of sleep quality. ${ }^{64}$ There are no consistent effects of first-generation antipsychotics on measures of sleep continuity and sleep structure, including the percentage of sleep stages or sleep and REM latency in healthy controls. Therefore, it is possible any effects of these high-potency typical antipsychotics may be indirect with improved sleep secondary to reduced stressful symptomatology.

In contrast, studies of the effects of the atypical antipsychotics (clozapine, olanzapine, quetiapine, risperidone, ziprasidone and paliperidone) in healthy controls and schizophrenia patients show a relatively consistent effect on measures of sleep continuity, with an increased total sleep time and/or sleep efficiency and individually varying effects on other sleep parameters, such as an increase in REM latency observed for olanzapine, quetiapine, and ziprasidone and an increase in SWS documented for olanzapine and ziprasidone. ${ }^{65,66}$ Additionally, clozapine and olanzapine demonstrate comparable influences on other sleep variables, such as SWS or REM density, in controls and schizophrenic patients. ${ }^{67,68}$ Therefore, it is possible that the effects of second generation antipsychotics observed on sleep in healthy subjects and schizophrenic patients might involve the action of these drugs on symptomatology, such as depression, cognitive impairment, and negative and positive symptoms.

Circadian rhythm abnormalities have been described in a number of small studies using actigraphy, often without matched controls. Mills et al showed robust circadian rhythms of both core body temperature and urinary electrolytes but a shorter than 24-hour sleep-wake cycle. ${ }^{69}$ Wirz-Justice et al demonstrated normal rest activity cycles in clozapine-treated patients compared to disordered circadian rhythms in those on typical neuroleptics, and proposed that mechanisms of drug action directly affected circadian rhythm. ${ }^{70}$ Decreased physical activity during the day was also shown using actigraphy in schizophrenia patients compared to both controls and depressive patients. ${ }^{71}$ Bromundt et al showed highly variable sleep-wake cycles in 14 patients with more robust sleep-wake cycles correlating with better frontal lobe function, again highlighting a link between impaired sleep and worse cognition. ${ }^{72}$ The most recent and detailed analysis of circadian rhythm, which included prolonged actigraphy and melatonin profiles in 20 schizophrenia patients compared to 21 unemployed controls, found marked circadian rhythm abnormalities, including both delayed sleep-phase syndrome and free-running, non-24-hour circadian rhythm in 50\% of those studied, with no relationship to the neuroleptic used. ${ }^{73}$ A very recent study demonstrating disrupted sleep-wake rhythms in a mouse model of schizophrenia demonstrated intact retinal inputs to the SCN, but suggested a possible impairment of synaptic connectivity modulating the output from the SCN. ${ }^{74}$ Mouse models offer the potential for targeting the sleep and circadian rhythm disruption as a therapy for schizophrenia. ${ }^{75}$

Disrupted sleep and wake in schizophrenia may be intrinsic to the disease itself or occur as a consequence of psychotropic medication, but it may also be due to a primary sleep disorder. This remains a somewhat neglected and potentially treatable aspect of sleep disturbance within this population. There is now increasing recognition of the association between schizophrenia and sleep-related breathing disorders, possibly related, in part, to the weight gain associated with atypical antipsychotics. Metabolic syndrome was found in $38 \%$ of a community-based psychiatric cohort on long-term antipsychotics. ${ }^{76}$ A number of studies have found high rates of sleep apnea in both hospital and community-based populations. ${ }^{77,78}$ However, not all studies have used control groups, and it has been suggested that sleep apnea is so common in the increasingly obese general population that these rates may not differ to those of BMI matched controls. ${ }^{79}$ To the authors' knowledge, there have been no cross-sectional or prospective studies of psychiatric patients with metabolic syndrome to assess the prevalence of OSA. Previous inpatient studies have shown that obese patients with chronic psychiatric morbidity have high rates of OSA. ${ }^{80}$ Occasional case reports have highlighted the benefits of continuous positive airway-pressure treatment on symptomatology in schizophrenia ${ }^{81-83}$ but there are no prospective trials to assess long-term benefit or tolerability of continuous positive airway-pressure therapy in comparison to normal controls.

There are some hypotheses that periodic limb movements are not increased in those with schizophrenia, ${ }^{77}$ but there is very little data regarding the prevalence of other primary sleep disorders, including restless legs and parasomnias.

With regards to insomnia, symptoms are common in those with high degrees of paranoia ${ }^{84}$ and, recently, the first structured pilot trial of cognitive behavioral therapy for insomnia was carried out in 15 patients with fixed and treatment-resistant psychosis. ${ }^{85}$ This showed a promising outcome with a significant improvement not just in sleep outcomes in two-thirds of subjects, but reduced persecutory 
delusions in 50\%. Larger and longer-term trials are needed with control groups to assess the long-term benefits of such behavioral therapies.

\section{Major depressive disorder}

Sleep complaints and depression are bidirectionally related, and there has possibly been more general focus on the role of sleep disturbance in depression than in any other psychiatric disorder with sleep disturbance included within the Diagnostic and Statistical Manual of Mental Disorders Fourth Edition (DSM-IV) diagnostic criteria. ${ }^{21}$ Epidemiologic studies confirm poor sleep quality in 50\%-90\% of those with diagnosed depression, ${ }^{86,87}$ and the high prevalence of depression in insomnia patients has already been discussed, ${ }^{24}$ with insomnia emerging as a clear risk factor for subsequent depression and conferring a worse outcome in those already depressed. Despite methodological differences, sleep disturbance is one of the most important predictors of a subsequent depressive relapse. The discovery that complete SD exerts a potent antidepressant effect therefore seems paradoxical, but much of the original interest in the relationship between sleep and mood stemmed from experiments in the 1970s by Wirz-Justice and Van den Hoofdakker, among others, to show that a single night of complete SD leads to a rapid and dramatic improvement of mood in up to $60 \%$ of patients. ${ }^{88}$ However, the effect is short-lived, with immediate relapse after normal sleep, sometimes after even a brief nap.

The polysomnography changes that occur during depression have been studied from the 1960s, and a number of studies have consistently shown a reduction in sleep efficiency, decreased SWS and disinhibited REM sleep with shortened REM latency, a longer first REM cycle, and increased REM density (the number of eye movements during REM) ${ }^{89,90}$ Decreased REM latency was initially thought to be a marker for primary rather than secondary depression, but subsequent studies failed to show the same result. ${ }^{91}$ More detailed analysis of SWS has shown a reduction in delta waves, particularly in the first half of the night and correlated to symptom severity. ${ }^{92}$ However, to date, no single sleep variable has been of sufficient specificity to be diagnostic for any one psychiatric illness.

One key question has been whether sleep abnormalities only occur acutely during depressive relapse as a "statedependent" marker, or are present prior to symptom onset and confer a vulnerability to subsequent mood disorder as a "trait" marker. However, this area is complicated by the effects of medication on polysomnography studies. Researchers have shown REM sleep normalizes after depression treatment, but many of the pharmacotherapies and in particular the antidepressants are known to lengthen REM latency and improve sleep continuity in both patients and normal controls. ${ }^{93,94}$ However, increased sleep efficiency and REM sleep improvement has also been demonstrated after nonpharmacological therapies such as cognitive behavioral therapy. ${ }^{95,96}$ Conversely, several studies have shown that changes such as shortened REM latencies persist during remission, and longitudinal studies have shown a stable REM latency over time, suggesting at least some trait markers of at least some of the sleep changes. ${ }^{97}$ In further support of a trait marker is the finding of similar REM sleep changes in subjects with a strong family history of depression but no symptoms at the time of study. ${ }^{98}$

Although up to $20 \%$ of patients complain of hypersomnia, there are few polysomnographic studies of this group, and multiple sleep latency tests and measured total sleep time in this group are often normal. ${ }^{99,100}$ The same is true of seasonal affective disorder, despite complaints of hypersomnia, ${ }^{101}$ suggesting that this is not the same sleepiness that can be objectively demonstrated in conditions such as idiopathic hypersomnia. Possible confounding factors include different subtypes of depression within studies and variable tools used to assess daytime sleepiness.

\section{Effect of antidepressant therapies on sleep}

Total SD has been mentioned earlier as the only therapy with proven effect within 24 hours; however, rapid relapse is the norm after a single night of recovery sleep, making it of little therapeutic benefit. Both timing and dose of SD have been used to try and obtain therapeutic benefit,with little success to date. ${ }^{102}$ Selective REM suppression has been used, and one early study showed a treatment response comparable to imipramine, ${ }^{103}$ but later studies still showed greater benefit with total SD. ${ }^{104}$ Bright light may add some further benefit in depression, but there is better evidence for its benefit in seasonal affective disorder. ${ }^{105,106}$ Almost all antidepressant medications modify sleep architecture, making sleep changes in patients in remission hard to interpret. Most tricyclic antidepressants increase total sleep time and decrease wake time after sleep onset, while many selective serotonin reuptake inhibitors have the opposite effect. However, almost all antidepressants prolong REM sleep latency and reduce the amount of REM sleep. Both depressed patients and healthy volunteers have a decreased dream-recall frequency under treatment with antidepressants. This is a consistent effect in tricyclic antidepressants, less 
consistently documented for selective serotonin reuptake inhibitors/serotonin norepinephrine reuptake inhibitors. Withdrawal from antidepressants may cause nightmares and intensify dreaming; ${ }^{107,108}$ however, this antidepressant effect is not dependent upon REM sleep elimination and there is no clear evidence that the mechanism of action of antidepressants is dependent on REM sleep suppression.

The role of circadian rhythm abnormalities in the pathophysiology remains unclear. While elevated cortisol is consistently seen in at least $50 \%$ of depressed patients at night, levels fall in remission and the effect is not specific to depression. ${ }^{109}$ Some advocate regular sleep-wake rhythms and avoidance of SD to avoid relapse. ${ }^{110}$ One recent study showed that a chronotherapeutic regime (bright light and sleep stabilization) significantly improved outcomes over a 9-week period, ${ }^{111}$ but there is a lack of longitudinal data. It is clearly an area that warrants further study with well-defined diagnostic groups.

\section{Bipolar disorder}

Sleep disturbance is a core feature of bipolar disorder (BD), being included in DSM-IV ${ }^{21}$ diagnostic criteria for major depressive episodes, mania, and hypomania, and it is also commonly reported between mood episodes. ${ }^{112}$ Disturbances in circadian rhythm are also present, ${ }^{113}$ and it is now thought that sleep and circadian disturbances, rather than being an artifact of mood episodes, are a core part of the underlying etiology and maintenance of BD. ${ }^{114}$ This view is supported by the evidence of sleep and circadian disturbances in the initial prodrome of the illness and in the prodrome of relapse. Children at high risk for developing BD have increased sleep disturbances preceding the first episode, ${ }^{115-119}$ including difficulty getting to sleep, fragmented sleep, and decreased sleep. ${ }^{120,121}$ Sleep disturbances are reported as an early symptom of bipolar depression $(17 \%-57 \%$ of subjects [median 24\%]) and are the most robust prodromal symptom of mania reported by 53\%-90\% (median 77\%) of subjects preceding a manic episode. ${ }^{122}$ Enforced SD can lead to the onset of manic or hypomanic episodes, ${ }^{123}$ although the literature is inconsistent, probably due to poor characterization of unipolar and bipolar subjects and post hoc follow-up. ${ }^{124}$ However, in a well-defined group of 206 inpatients with DSMIIIR- and DSM-IV-defined bipolar depression, switch rates of $4.85 \%$ to mania and $5.83 \%$ to hypomania were observed following three cycles of total SD. ${ }^{125}$

\section{Sleep during mania}

Polysomnography studies consistently found shortened sleep time, shorter REM latency, increased REM density, and more disturbed sleep. ${ }^{126-129}$ Manic patients report a decreased need for sleep in $69 \%-100 \%$ of subjects studied.

\section{Sleep and bipolar depression}

Sleep disturbances during bipolar depression are common but follow a less consistent pattern than during mania. Hypersomnia is reported in between $23 \%$ and $78 \%$ of subjects and rates of insomnia vary considerably, with one study of patients. Polysomnography studies comparing patients with bipolar depression to unipolar depression and healthy controls report inconsistent results with greater fragmentation of REM sleep, lower REM latency, no difference in REM latency, increased REM density, fewer minutes in stage 1 sleep, and prolonged SWS latency all reported. ${ }^{126}$ The decrease in REM latency and higher REM density compared to healthy controls is probably the most consistent finding. ${ }^{130-133}$

\section{Sleep during euthymia}

Polysomnography studies show greater REM density in euthymic BD patients than in controls, ${ }^{134,135}$ as well as more overnight arousals with increased REM sleep. ${ }^{134,136}$ Clinically significant sleep disturbance was found in $70 \%$ of

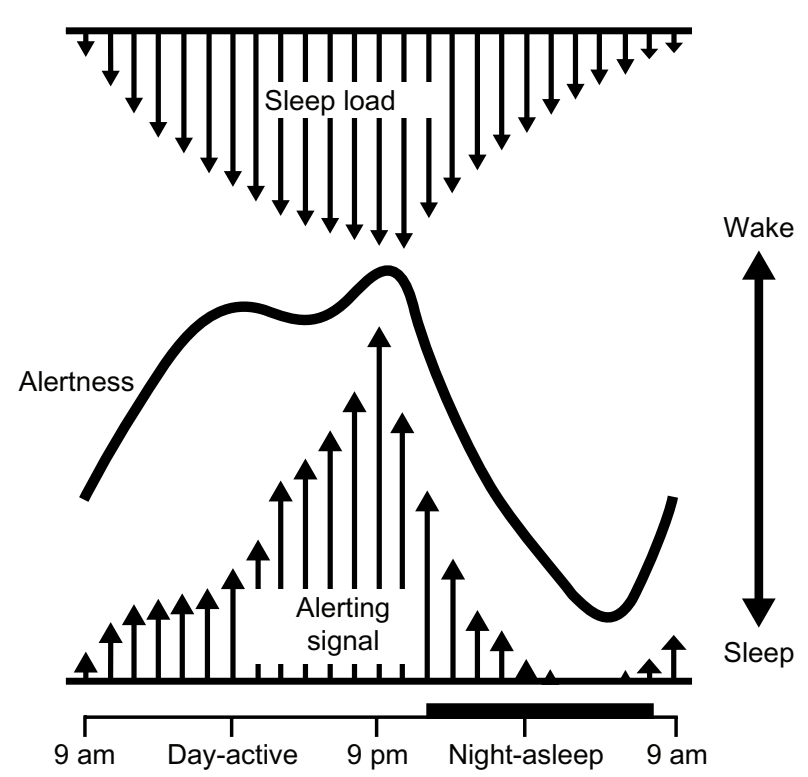

Figure I Homeostatic sleep propensity (sleep load) increases through the waking day and is dissipated by sleep.

Notes: The alerting signal is generated by the circadian system and opposes the increasing sleep load peaking in the late evening in order to maintain wakefulness for approximately 16 hours. The circadian drive for alertness then decreases overnight in order that as sleep load decreases sleep can still be maintained for approximately 8 hours.

Reproduced from Physiology and Behaviour; 90, Beersma DGM and Gordijn MCM, Circadian Control of the Sleep-Wake Cycle 190-195, Copyright (2007), with permission from Elsevier. 221 
euthymic BD patients with 55\% meeting diagnostic criteria for insomnia by Harvey et al. ${ }^{12}$ Compared to insomniacs and good sleepers, BD patients had lower sleep efficiency and lower daytime activity levels. Subjectively, BD patients report sleep difficulties that are more severe than in controls but less severe than in the insomnia group, and suffer more daytime sleepiness according to the Epworth Sleepiness Scale. ${ }^{137}$ Hypersomnia has also been reported in euthymic BD patients with $25 \%$ of patients meeting the criteria in one study. ${ }^{138}$

In summary, studies of euthymic BD patients indicate that there are significant sleep disturbances and variability in sleep, present in the absence of major mood episodes.

\section{Sleep function and course of illness in BD}

Given the possibility that sleep disturbances may have a causal role in the relapse and maintenance of bipolar disorder, several studies have examined associations between sleep function and course of illness. In a polysomnography study, REM and stage 2 sleep were not found to correlate with current symptoms, but duration of the first REM period and amount of SWS did correlate positively with manic symptoms and impairment measured on the Work And Social Adjustment Scale 3 months later. ${ }^{139}$ REM density was positively correlated with depressive symptoms and impairment at 3 months, and the amount of stage 2 sleep was negatively correlated with manic symptoms and impairment. In a study utilizing sleep diaries and semi-structured interviews, ${ }^{135}$ lower and more variable sleep efficiency and more variable total wake time were associated with more lifetime depressive episodes. Variability in time to fall asleep was positively correlated with concurrent manic symptoms. Hypersomnia has also been found to correlate with future depressive symptoms at 6 months. ${ }^{138}$ These studies suggest that sleep architecture may have a mechanistic role in disease process.

\section{Circadian rhythms in BD}

Circadian rhythm disturbance is reported in $\mathrm{BD}$ and may be at least partially responsible for the pattern of disturbed sleep evident in BD patients. Several actigraphy studies have found evidence of disturbed circadian rhythms in BD patients, including phase advances and greater variability in sleep patterns. ${ }^{140,141}$ A number of circadian genes have been linked to susceptibility to developing BD, including CLOCK, ARNTL 1-2, PER1-3, and CRY1-2. ${ }^{142}$ Overall, however, findings associating circadian genes to $\mathrm{BD}$ are inconsistent. Several reports indicate BD patients are more likely to be evening types, ${ }^{143-146}$ suggesting a circadian phase delay in BD. However, actigraphy-based studies have found variable results, with advanced sleep phase, delayed sleep phase, and very irregular sleep-wake cycles all found, as well as some groups showing few abnormalities. One consistent finding was reduced total activity compared to controls. ${ }^{141,147}$ Poor social rhythm regularity predicted the time to the next mood episode. ${ }^{148}$

Differences in the secretion of melatonin, and sensitivity of melatonin secretion to light, have also been reported in BD. Earlier studies ${ }^{149-151}$ suggested a supersensitivity to light in BD patients, with nighttime melatonin levels falling more compared to controls; later, larger studies did not find these changes, but did consistently show lower peak levels of melatonin with and without light stimulus and a less robust circadian rhythm to melatonin secretion. ${ }^{152-154}$ Recent evidence of lower activity of a key enzyme involved in melatonin synthesis (acetyleserotonin O-methlytransferase) in $\mathrm{BD}$ patients compared to controls suggests a general role

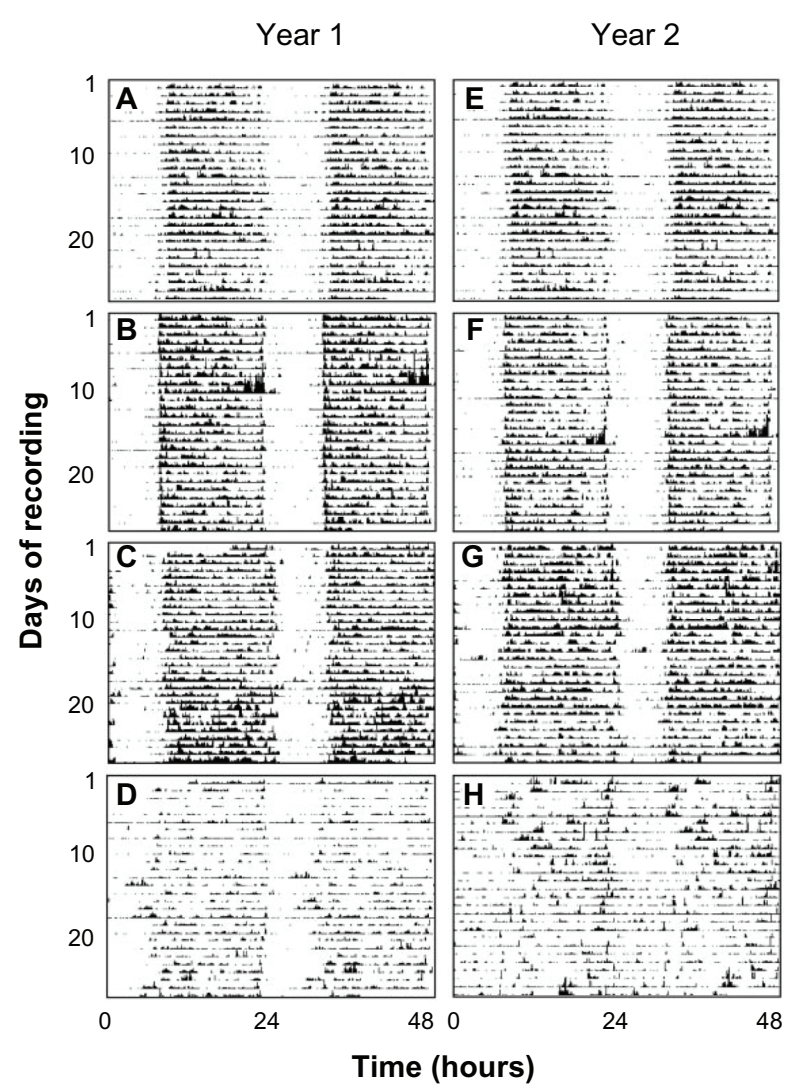

Figure 2 Representative actograms from healthy control (A and E), mildly demented (B and $\mathbf{F}$ ) and moderately demented (C, G, D and $\mathbf{H})$ subjects recorded first in year I $(\mathbf{A} \pm \mathbf{D})$, and for the same subjects at follow-up in year $2(\mathbf{E} \pm \mathbf{H})$.

Note: Data from 28 consecutive days are double plotted on a 48 -hour time base for clarity.

From Hatfield CF et al. Disrupted daily activity/rest cycles in relation to daily cortisol rhythms of home-dwelling patients with early Alzheimer's dementia, Brain, 2004, 27, part 5, I06 I-74, by permission of Oxford University Press. ${ }^{178}$ 
of melatonin as a susceptibility factor for the development of BD. ${ }^{155}$ Ramelteon, a selective melatonin MT1/MT2 agonist, may be effective in preventing relapse in euthymic bipolar patients, ${ }^{156}$ and agomelatine may be effective as an additional therapy for the treatment of bipolar depression. ${ }^{157}$ Collectively, these studies demonstrate abnormalities in circadian rhythms in patients with BD. Therefore, chronotherapeutics (controlled exposure to environmental stimuli that act on biological rhythms), such as SD, light, and dark therapy may be useful interventions for BD and some small studies have shown this to be the case. ${ }^{113,158,159}$ Studies have also demonstrated the efficacy of interpersonal social rhythm therapy, which aims to stabilize social rhythms in preventing BD relapse. ${ }^{160,161}$

\section{Primary sleep disorders in BD}

The prevalence of sleep apnea in BD patients has not been systematically evaluated, despite the high frequency of risk factors such as overweight and obesity. ${ }^{162,163}$ A recent study using a self-assessment tool to establish the risk of OSA found $54.1 \%$ of 72 bipolar I disorder patients were at a high risk of OSA. Despite a number of pharmacotherapies for BD being known to exacerbate restless legs, there have been very few studies of the prevalence of restless legs or periodic limb movements.

\section{Neurodegenerative diseases Aging and sleep}

Given the strong association of neurodegenerative conditions with aging, it is important to understand the changes that occur within the sleep-wake cycle and circadian rhythm in an older population. As we age, total sleep time is slightly reduced compared to younger adults, with decreasing amounts of SWS, increased sleep latency, and increased sleep fragmentation during the night. ${ }^{164}$

Disruptions in the sleep-wake cycle and sleep complaints are commonly found in community-based studies of older people. Over $50 \%$ of adults aged over 65 have at least one chronic sleep-related problem. ${ }^{165,166}$ Older adults also have high rates of primary sleep disorders. Sleep-related breathing disorders, in particular OSA, are estimated at rates of $10 \%-20 \% .{ }^{167-170}$ Insomnia and restless legs are also increasingly frequent in the people over $65 .{ }^{171,172}$ Changes in circadian rhythms have also been demonstrated with advancing age, with a decline in the cortisol and melatonin rhythms that entrain day-night activity patterns. ${ }^{173,174}$ With aging there is reduced amplitude of the circadian rhythm, a phase shift (in particular a phase advance), ${ }^{175}$ and a loss of the robustness of the rhythm (weakening of the rhythmic pattern). However, within older populations, there is significant circadian rhythm variability between individuals, with some hypothesizing that an age-related disruption to the SCN is responsible. ${ }^{176}$

\section{Alzheimer's disease (AD)}

Sleep disturbance is one of the most common reasons for institutionalization of demented elderly patients. ${ }^{177}$ From $25 \%-50 \%$ of the demented elderly suffer from severe nocturnal restlessness, often called "sundowning," at some stage of the disease. Activity monitoring (actigraphy) in both early and late $\mathrm{AD}^{178-180}$ and in other dementias in patients at home and in institutions confirms profoundly disrupted circadian rhythms in those with moderate and severe dementia.

A recent large trial of bright light therapy and melatonin in institutionalized patients showed modest benefits in measures of daytime function with light therapy alone and together with melatonin; ${ }^{181}$ however, a further trial of melatonin alone showed no significant improvement in daytime function or night sleep. ${ }^{182}$

In patients with $\mathrm{AD}$, certain changes can be seen as an exaggeration of the normal aging changes with polysomnography showing increased numbers of awakenings and therefore increased stage 1 sleep. Compared to normal controls there is also reduced SWS. ${ }^{183-186}$ These changes are consistently reported across moderate to severe AD patients and sleep disturbance worsens with increasing severity of AD. The apolipoprotein status has been associated with progression of sleep-wake disturbance. ${ }^{187}$ Another feature of the polysomnogram in AD that suggests accelerated aging is a loss of some of the distinctive features of stage 2 sleep with poorly formed sleep spindles that are of shorter duration and less numerous. ${ }^{188}$ As the disease progresses, NREM sleep stages become progressively more difficult to stage, although REM sleep duration remains relatively stable and loss of REM atonia or significant REM sleep behavior disorder is uncommon. ${ }^{189}$

\section{Parkinson's disease (PD)}

In his elegant monograph published in 1817, James Parkinson gave his name to a progressive neurological disease characterized by stiffness, slowness, and tremor. ${ }^{190}$ In the last 10 years, there has been increasing clinical and research interest in the nonmotor symptoms of the disease. Sleep disturbance, depression, and cognitive impairment are all frequently seen in PD and are often considered to be more disabling than the abnormal movement. ${ }^{191,192}$ Sleep disturbance is near universal in advanced disease and some sleep symptoms can predate 
all other motor phenomena. ${ }^{193}$ Particular mention should be made of the association between REM behavior disorder (REMBD) and Parkinsonian syndromes.

Carlos Schenck first described a group of patients with apparently idiopathic REMBD who went on to develop Parkinsonian syndromes including dementia with Lewy bodies (DLB), PD, and multiple system atrophy. ${ }^{194}$

REMBD affects approximately $0.5 \%$ of elderly males, with patients acting out increasingly violent with vivid dreams that often result in injury to themselves or their bed partners. ${ }^{195}$ It is frequently well treated with long-acting hypnotics such as clonazepam. It is now known that a patient presenting to the sleep clinic with typical REMBD will have a $50 \%$ chance of developing a Parkinsonian syndrome within 5 years. ${ }^{196,197}$ A number of other symptoms can predate the onset of PD such as impaired olfaction, constipation, and mood disturbance but REMBD has the highest specificity as a biomarker raising the possibility of targeting coming neuroprotective agents at patients with this condition. Some patients, however, can develop symptoms many years before the development of any other neurodegenerative problem. ${ }^{198}$ Conversely, 40\% of patients in a movement disorders clinic with PD will have REMBD and $95 \%$ of those will have multiple system atrophy. ${ }^{199}$ Interestingly, this association between REMBD and subsequent neurodegeneration is much more strongly associated with alpha synucleinopathies, including PD, multiple system atrophy, and DLB, but not with tauopathies, such as AD or progressive supranuclear palsy where a far smaller percentage of patients have loss of REM atonia or symptomatic REMBD and this diagnosis has been shown to improve differential diagnosis with these conditions. ${ }^{189,200}$ There is an increasingly clear association between REMBD and increased risk of the subsequent development of dementia and daytime visual hallucinations. ${ }^{201}$

Daytime sleepiness was also highlighted in PD patients, particularly with the advent of newer dopamine agonists and the growing reports of "sleep attacks" in association with this group of drugs. ${ }^{202}$ Patients with PD need to be cautioned about possible daytime sleepiness when they start dopamine agonists. However, daytime sleepiness in PD is often multifactorial with many case control studies highlighting a large number of potential causes including severe REMBD, nocturia, and nighttime pain caused by immobility and tremor. ${ }^{191,203}$ Increased rates of both central and OSA have been described in those with moderate and advanced PD and there is also an increase in periodic limb movements and restless legs. ${ }^{204}$ Although some authors have suggested a possible disruption of the circadian rhythm in those with PD, to date, controlled studies are lacking. There is also a relative lack of prospective studies to determine which sleep disorders emerge at different stages of the disease and which therapies best improve night sleep and subsequent daytime function.

A careful sleep history should be taken in all patients with PD and sleep symptoms monitored throughout the disease. PD must be reported to the Driver and Vehicle

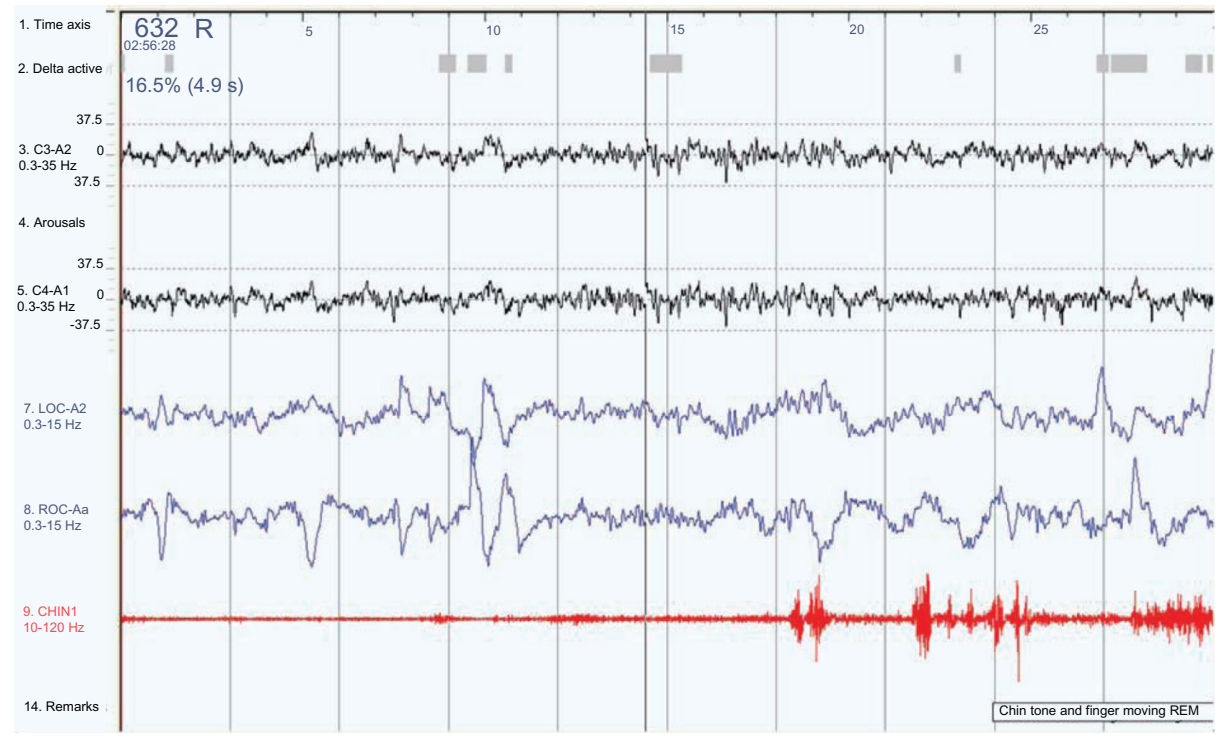

Figure 3 A 30-second epoch from a polysomnograph demonstrating the changes in REM behavior disorder.

Notes: The electrooculogram channels (LOC and ROC; blue) show the characteristic eye flicks of REM sleep. The submental electromyogram (CHIN I; red) should be flat but shows phasic activity as the patient is moving.

Abbreviations: LOC, left outer canthus of the eye; REM, rapid eye movement; ROC, right outer canthus of the eye. 
Licensing Authority in the UK and clinicians must include an assessment of sleepiness. Recent data show that PD patients themselves are poor judges of their safety behind the wheel ${ }^{205}$ but a recent review highlights the lack of standardized criteria to ensure safety behind the wheel. ${ }^{206}$

\section{Dementia with Lewy bodies (DLB)}

There is less information on nocturnal sleep disturbance in DLB compared to AD, but recent studies suggest an even greater level of nighttime sleep disturbance with an increase in hallucinations, agitation, and apathy but a less clear relationship to disease progression. ${ }^{207}$ RBD remains a distinguishing feature within the history of a dementing patient that allows for greater sensitivity in diagnosis when present, but there is very limited data on other primary sleep disorders within this group alone..$^{208-210}$ A recent large cross-sectional study across a number of dementia subtypes highlights RBD as distinguishing DLB and PD dementia from vascular dementia and $\mathrm{AD}$ and also the need to look for other sleep disorders, such as sleep apnea, which were frequent, particularly in vascular dementia. ${ }^{211}$

\section{Frontotemporal dementia}

A single study using actigraphy and sleep diaries showed disturbed circadian rhythms in frontotemporal dementia, ${ }^{212}$ but this was less marked than that seen in $\mathrm{AD}$ and did not clearly relate to disease progression. Comparison between the polysomnography studies of those with AD compared to frontotemporal dementia showed greater REM sleep disruption in $\mathrm{AD}$, again suggesting that sleep in frontotemporal dementia may be better preserved. ${ }^{213}$

\section{Huntington's disease (HD)}

HD is a well-described hereditary, neurodegenerative disease characterized by cognitive decline, behavioral change, and chorea, and patients often have particularly fragmented sleep, with up to $88 \%$ reporting sleep problems. ${ }^{214}$ A wide range of sleep problems, including increased movements during sleep, prolonged sleep latency, and nocturnal waking and daytime sleepiness, have all been reported. ${ }^{215}$ Unlike a number of other neurodegenerative conditions, patients with HD showed increased density of sleep spindles compared to healthy controls. ${ }^{216}$ The sleep disturbance correlates with the degree of cognitive impairment and depression. ${ }^{217}$

Studies looking at the frequency of sleep-disordered breathing have shown variable results. A small pathophysiological study of five patients showed a subtle reduction of hypocretinergic neurons $(27 \%)$ postmortem but cerebrospinal fluid hypocretin levels were normal in two studies of HD patients. ${ }^{218,219}$ Polysomnography studies of HD patients have shown reduced REM sleep and delayed REM sleep latency in those with established disease but also in premanifest disease with an increase in periodic limb movements, sleep apnea, and daytime sleepiness. ${ }^{220}$

\section{Summary}

Sleep is vital for normal brain function and there is a complex bidirectional relationship between disturbed sleep and cognitive and mental health disturbance. Much research still needs to be done to characterize the different sleep patterns that occur within different diseases to see whether sleep patterns can be used as specific biomarkers of disease or, possibly more importantly, as trait markers for subsequent illness. It is still unknown whether intervening to normalize sleep clearly improves the outcome of chronic mental health problems or neurodegenerative disease, and there is an urgent need for increasing recognition of the role of disturbed sleep in a disturbed brain.

\section{Disclosure}

The authors report no conflicts of interest in this work.

\section{References}

1. Fuller PM, Gooley JJ, Saper CB. Neurobiology of the sleep-wake cycle: sleep architecture, circadian regulation, and regulatory feedback. J Biol Rhythms. 2006;21(6):482-493.

2. Iber C, Ancoli-Israel S, Chesson A, Quan S, editors. The American Academy of Sleep Medicine Manual for the Scoring of Sleep and Associated Events: Rules, Terminology and Technical Specifications. Westchester, Illinois: Amercian Academy of Sleep Medicine; 2007.

3. Borbély AA. A two process model of sleep regulation. Hum Neurobiol. 1982;1(3):195-204.

4. Takahashi JS, Hong HK, Ko CH, McDearmon EL. The genetics of mammalian circadian order and disorder: implications for physiology and disease. Nat Rev Genet. 2008;9(10):764-775.

5. Czeisler CA, Duffy JF, Shanahan TL, et al. Stability, precision, and near-24-hour period of the human circadian pacemaker. Science. 1999;284(5423):2177-2181.

6. Freedman MS, Lucas RJ, Soni B, et al. Regulation of mammalian circadian behavior by non-rod, non-cone, ocular photoreceptors. Science. 1999;284(5413):502-504.

7. Goel N, Rao H, Durmer JS, Dinges DF. Neurocognitive consequences of sleep deprivation. Semin Neurol. 2009;29(4):320-339.

8. Lim J, Dinges DF. A meta-analysis of the impact of short-term sleep deprivation on cognitive variables. Psychol Bull. 2010;136(3):375-389.

9. Fortier-Brochu E, Beaulieu-Bonneau S, Ivers H, Morin CM. Insomnia and daytime cognitive performance: a meta-analysis. Sleep Med Rev. 2012;16(1):83-94.

10. Beebe DW, Groesz L, Wells C, Nichols A, McGee K. The neuropsychological effects of obstructive sleep apnea: a meta-analysis of norm-referenced and case-controlled data. Sleep. 2003;26(3): 298-307.

11. Blatter K, Cajochen C. Circadian rhythms in cognitive performance: methodological constraints, protocols, theoretical underpinnings. Physiol Behav. 2007;90(2-3):196-208. 
12. Reid KJ, McGee-Koch LL, Zee PC. Cognition in circadian rhythm sleep disorders. Prog Brain Res. 2011;190:3-20.

13. Koslowsky M, Babkoff H. Meta-analysis of the relationship between total sleep deprivation and performance. Chronobiol Int. 1992;9(2):132-136.

14. Pilcher JJ, Huffcutt AI. Effects of sleep deprivation on performance: a meta-analysis. Sleep. 1996;19(4):318-326.

15. Philibert I. Sleep loss and performance in residents and nonphysicians: a meta-analytic examination. Sleep. 2005;28(11):1392-1402.

16. Ancoli-Israel S, Roth T. Characteristics of insomnia in the United States: results of the 1991 National Sleep Foundation Survey. I. Sleep. 1999;22 Suppl 2:S347-S353.

17. Ohayon MM. Prevalence of DSM-IV diagnostic criteria of insomnia: distinguishing insomnia related to mental disorders from sleep disorders. J Psychiatr Res. 1997;31(3):333-346.

18. Weissman MM, Greenwald S, Niño-Murcia G, Dement WC. The morbidity of insomnia uncomplicated by psychiatric disorders. Gen Hosp Psychiatry. 1997;19(4):245-250.

19. Leger D, Guilleminault C, Dreyfus JP, Delahaye C, Paillard M. Prevalence of insomnia in a survey of 12,778 adults in France. J Sleep Res. 2000;9(1):35-42.

20. National Institutes of Health. National Institutes of Health State of the Science Conference statement on Manifestations and Management of Chronic Insomnia in Adults, June 13-15, 2005. Sleep. 2005;28(9):1049-1057.

21. American Psychiatric Association. Diagnostic and Statistical Manual of Mental Disorders, 4th ed. Arlington, VA: American Psychiatric Association; 2000.

22. American Academy of Sleep Medicine. International Classification of Sleep Disorders, 2nd ed. Arlington, VA: American Academy of Sleep Medicine; 2005.

23. Katz DA, McHorney CA. Clinical correlates of insomnia in patients with chronic illness. Arch Intern Med. 1998;158(10):1099-1107.

24. Ford DE, Kamerow DB. Epidemiologic study of sleep disturbances and psychiatric disorders. An opportunity for prevention? JAMA 1989;262(11):1479-1484.

25. McCall WV. A psychiatric perspective on insomnia. J Clin Psychiatry. 2001;62 Suppl 10:27-32.

26. Ancoli-Israel S. The impact and prevalence of chronic insomnia and other sleep disturbances associated with chronic illness. Am J Manag Care. 2006;12(Suppl 8):S221-S229.

27. Chang PP, Ford DE, Mead LA, Cooper-Patrick L, Klag MJ. Insomnia in young men and subsequent depression. The Johns Hopkins Precursors Study. Am J Epidemiol. 1997;146(2):105-114.

28. Jaussent I, Bouyer J, Ancelin ML, et al. Insomnia and daytime sleepiness are risk factors for depressive symptoms in the elderly. Sleep. 2011;34(8):1103-1110.

29. Fong SY, Wing YK. Longitudinal follow up of primary insomnia patients in a psychiatric clinic. Aust N ZJ Psychiatry. 2007;41(7):611-617.

30. Buysse DJ, Angst J, Gamma A, Ajdacic V, Eich D, Rössler W. Prevalence, course, and comorbidity of insomnia and depression in young adults. Sleep. 2008;31(4):473-480.

31. Baglioni C, Battagliese G, Feige B, et al. Insomnia as a predictor of depression: a meta-analytic evaluation of longitudinal epidemiological studies. J Affect Disord. 2011;135(1-3):10-19.

32. Pigeon WR, Hegel M, Unutzer J, et al. Is insomnia a perpetuating factor for late-life depression in the IMPACT cohort? Sleep. 2008;31(4): 481-488.

33. Johnson EO, Chilcoat HD, Breslau N. Trouble sleeping and anxiety/ depression in childhood. Psychiatry Res. 2000;94(2):93-102.

34. Pigeon WR. Treatment of adult insomnia with cognitive-behavioral therapy. J Clin Psychol. 2010;66(11):1148-1160.

35. Mitchell MD, Gehrman P, Perlis M, Umscheid CA. Comparative effectiveness of cognitive behavioral therapy for insomnia: a systematic review. BMC Fam Pract. 2012;13:40.

36. Kapella MC, Herdegen JJ, Perlis ML, et al. Cognitive behavioral therapy for insomnia comorbid with COPD is feasible with preliminary evidence of positive sleep and fatigue effects. Int J Chrom Obstruct Pulmon Dis 2011;6:625-635.
37. Ritterband LM, Bailey ET, Thorndike FP, Lord HR, Farrell-Carnahan L, Baum LD. Initial evaluation of an Internet intervention to improve the sleep of cancer survivors with insomnia. Psychooncology. 2012;21(7): 695-705.

38. Belleville G, Cousineau H, Levrier K, St-Pierre-Delorme MÈ. Meta-analytic review of the impact of cognitive-behavior therapy for insomnia on concomitant anxiety. Clin Psychol Rev. 2011;31(4):638-652.

39. Lancee J, van den Bout J, van Straten A, Spoormaker VI. Baseline depression levels do not affect efficacy of cognitive-behavioral self-help treatment for insomnia. Depress Anxiety. 2013;30(2):149-156.

40. Wagley JN, Rybarczyk B, Nay WT, Danish S, Lund HG. Effectiveness of abbreviated CBT for insomnia in psychiatric outpatients: sleep and depression outcomes. J Clin Psychol. Epub October 26, 2012.

41. Wheaton AG, Perry GS, Chapman DP, Croft JB. Sleep disordered breathing and depression among US adults: National Health and Nutrition Examination Survey, 2005-2008. Sleep. 2012;35(4):461-467.

42. Harris M, Glozier N, Ratnavadivel R, Grunstein RR. Obstructive sleep apnea and depression. Sleep Med Rev. 2009;13(6):437-444.

43. Giles TL, Lasserson TJ, Smith BH, White J, Wright J, Cates CJ Continuous positive airways pressure for obstructive sleep apnoea in adults [review]. Cochrane Database Syst Rev. 2006;3:CD001106.

44. Wells RD, Freedland KE, Carney RM, Duntley SP, Stepanski EJ. Adherence, reports of benefits, and depression among patients treated with continuous positive airway pressure. Psychosom Med. 2007;69(5): 449-454.

45. Tandon R, Shipley JE, Taylor S, et al. Electroencephalographic sleep abnormalities in schizophrenia. Relationship to positive/negative symptoms and prior neuroleptic treatment. Arch Gen Psychiatry. 1992;49(3):185-194.

46. Keshavan MS, Tandon R. Sleep abnormalities in schizophrenia: pathophysiological significance. Psychol Med. 1993;23(4):831-835.

47. Xiang YT, Weng YZ, Leung CM, Tang WK, Lai KY, Ungvari GS. Prevalence and correlates of insomnia and its impact on quality of life in Chinese schizophrenia patients. Sleep. 2009;32(1):105-109.

48. Caldwell DF, Domino EF. Electroencephalographic and eye movement patterns during sleep in chronic schizophrenic patients. Electroencaphalogr Clin Neurophysiol. 1967;22(5):414-420.

49. Ganguli R, Reynolds CF 3rd, Kupfer DJ. Electroencephalographic sleep in young, never-medicated schizophrenics. A comparison with delusional and nondelusional depressives and with healthy controls. Arch Gen Psychiatry. 1987;44(1):36-44.

50. Dement W. Dream recall and eye movements during sleep in schizophrenics and normals. J Nerv Ment Dis. 1955;122(3):263-269.

51. Zarcone V, Azumi K, Dement W, Gulevich G, Kraemer H, Pivik T. REM phase deprivation and schizophrenia II. Arch Gen Psychiatry. 1975;32(11):1431-1436.

52. Poulin J, Daoust AM, Forest G, Stip E, Godbout R. Sleep architecture and its clinical correlates in first episode and neuroleptic-naive patients with schizophrenia. Schizophr Res. 2003;62(1-2):147-153.

53. Chouinard S, Poulin J, Stip E, Godbout R. Sleep in untreated patients with schizophrenia: a meta-analysis. Schizophr Bull. 2004;30(4):957-967.

54. Mueller T, Dierks T, Fritze J, Maurer K. Functional brain imaging (mapping of EEG) in relation to psychopathologic changes in schizophrenia. Psychiatry Res. 1989;29(3):419-420.

55. Benson KL, Sullivan EV, Lim KO, Lauriello J, Zarcone VP Jr, Pfefferbaum A. Slow wave sleep and computed tomographic measures of brain morphology in schizophrenia. Psychiatry Res. 1996;60(2-3): $125-134$.

56. Sekimoto M, Kato M, Watanabe T, Kajimura N, Takahashi K. Cortical regional differences of delta waves during all-night sleep in schizophrenia. Schizophr Res. 2011;126(1-3):284-290.

57. Keshavan MS, Miewald J, Haas G, Sweeney J, Ganguli R, Reynolds CF. Slow-wave sleep and symptomatology in schizophrenia and related psychotic disorders. J Psychiatr Res. 1995;29(4):303-314.

58. Sarkar S, Katshu MZ, Nizamie SH, Praharaj SK. Slow wave sleep deficits as a trait marker in patients with schizophrenia. Schizophr Res. 2010;124(1-3):127-133. 
59. Yang C, Winkelman JW. Clinical significance of sleep EEG abnormalities in chronic schizophrenia. Schizophr Res. 2006;82(2-3):251-260.

60. Goder R, Boigs M, Braun S, et al. Impairment of visuospatial memory is associated with decreased slow wave sleep in schizophrenia. J Psychiatr Res. 2004;38(6):591-599.

61. Manoach DS, Cain MS, Vangel MG, Khurana A, Goff DC, Stickgold R. A failure of sleep-dependent procedural learning in chronic, medicated schizophrenia. Biol Psychiatry. 2004;56(12):951-956.

62. Manoach DS, Thakkar KN, Stroynowski E, et al. Reduced overnight consolidation of procedural learning in chronic medicated schizophrenia is related to specific sleep stages. J Psychiatr Res. 2010;44(2):112-120.

63. Cohrs $S$. Sleep disturbances in patients with schizophrenia : impact and effect of antipsychotics. CNS drugs. 2008;22(11):939-962.

64. Nofzinger EA, van Kammen DP, Gilbertson MW, Gurklis JA, Peters JL. Electroencephalographic sleep in clinically stable schizophrenic patients: two-weeks versus six-weeks neuroleptic-free. Biological Psychiatry. 1993;33(11-12):829-835.

65. Miller DD. Atypical antipsychotics: sleep, sedation, and efficacy. Prim Care Companion J Clin Psychiatry. 2004;6(Suppl 2):3-7.

66. Goder R, Fritzer G, Gottwald B, et al. Effects of olanzapine on slow wave sleep, sleep spindles and sleep-related memory consolidation in schizophrenia. Pharmacopsychiatry. 2008;41(3):92-99.

67. Gimenez S, Romero S, Gich I, et al. Sex differences in sleep after a single oral morning dose of olanzapine in healthy volunteers. Hum Psychopharmacol. 2011;26(7):498-507.

68. Armitage R, Cole D, Suppes T, Ozcan ME. Effects of clozapine on sleep in bipolar and schizoaffective disorders. Prog Neuropsychopharmacol Biol Psychiatry. 2004;28(7):1065-1070.

69. Mills JN, Morgan R, Minors DS, Waterhouse JM. The free-running circadian rhythms of two schizophrenics. Chronobiologia. 1977;4(4): 353-360.

70. Wirz-Justice A, Haug HJ, Cajochen C. Disturbed circadian rest-activity cycles in schizophrenia patients: an effect of drugs? Schizophr Bull. 2001;27(3):497-502.

71. Berle JO, Hauge ER, Oedegaard KJ, Holsten F, Fasmer OB. Actigraphic registration of motor activity reveals a more structured behavioural pattern in schizophrenia than in major depression. BMC Res Notes. 2010;3:149.

72. Bromundt V, Koster M, Georgiev-Kill A, et al. Sleep-wake cycles and cognitive functioning in schizophrenia. Br J Psychiatry. 2011;198(4): 269-276.

73. Wulff K, Dijk DJ, Middleton B, Foster RG, Joyce EM. Sleep and circadian rhythm disruption in schizophrenia. Br J Psychiatry. 2012;200(4):308-316.

74. Oliver PL, Sobczyk MV, Maywood ES, et al. Disrupted circadian rhythms in a mouse model of schizophrenia. Curr Biol. 2012;22(4): 314-319.

75. Pritchett D, Wulff K, Oliver PL, et al. Evaluating the links between schizophrenia and sleep and circadian rhythm disruption. $J$ Neural Transm. 2012;119(10):1061-1075.

76. Mackin P, Waton T, Watkinson HM, Gallagher P. A four-year naturalistic prospective study of cardiometabolic disease in antipsychotic-treated patients. Eur Psychiatry. 2012;27(1):50-55.

77. Ancoli-Israel S, Martin J, Jones DW, et al. Sleep-disordered breathing and periodic limb movements in sleep in older patients with schizophrenia. Biol Psychiatry. 1999;45(11):1426-1432.

78. Anderson KN, Waton T, Armstrong D, Watkinson HM, Mackin P. Sleep disordered breathing in community psychiatric patients. European $J$ Psychiat. 2002;26(2):86-95.

79. Takahashi KI, Shimizu T, Sugita T, Saito Y, Takahashi Y, Hishikawa Y. Prevalence of sleep-related respiratory disorders in 101 schizophrenic inpatients. Psychiatry Clin Neurosci. 1998;52(2):229-231.

80. Winkelman JW. Schizophrenia, obesity, and obstructive sleep apnea. J Clin Psychiatry. 2001;62(1):8-11.

81. Boufidis S, Kosmidis MH, Bozikas VP, Daskalopoulou-Vlahoyianni E, Pitsavas S, Karavatos A. Treatment outcome of obstructive sleep apnea syndrome in a patient with schizophrenia: case report. Int J Psychiatry Med. 2003;33(3):305-310.
82. Karanti A, Landén M. Treatment refractory psychosis remitted upon treatment with continuous positive airway pressure: a case report. Psychopharmacol Bull. 2007;40(1):113-117.

83. Sugishita K, Yamasue H, Kasai K. Continuous positive airway pressure for obstructive sleep apnea improved negative symptoms in a patient with schizophrenia. Psychiatry Clin Neurosci. 2010;64(6):665.

84. Freeman D, Pugh K, Vorontsova N, Southgate L. Insomnia and paranoia. Schizophr Res. 2009;108(1-3):280-284.

85. Myers E, Startup H, Freeman D. Cognitive behavioural treatment of insomnia in individuals with persistent persecutory delusions: a pilot trial. J Behav Ther Exp Psychiatry. 2011;42(3):330-336.

86. Casper RC, Redmond DE Jr, Katz MM, Schaffer CB, Davis JM, Koslow SH. Somatic symptoms in primary affective disorder. Presence and relationship to the classification of depression. Arch Gen Psychiatry. 1985;42(11):1098-1104.

87. Riemann D, Berger M, Voderholzer U. Sleep and depression results from psychobiological studies: an overview. Biol Psychol. 2001;57(1-3):67-103.

88. Wirz-Justice A, Van den Hoofdakker RH. Sleep deprivation in depression: what do we know, where do we go? Biol Psychiatry. 1999;46(4):445-453.

89. Kupfer DJ, Foster FG. Interval between onset of sleep and rapid-eye-movement sleep as an indicator of depression. Lancet. 1972;2(7779):684-686.

90. Kempenaers C, Kerkhofs M, Linkowski P, Mendlewicz J. Sleep EEG variables in young schizophrenic and depressive patients. Biol Psychiatry. 1988;24(7):833-838.

91. Thase ME, Kupfer DJ, Spiker DG. Electroencephalographic sleep in secondary depression: a revisit. Biol Psychiatry. 1984;19(6): 805-814.

92. Perlis ML, Giles DE, Buysse DJ, Thase ME, Tu X, Kupfer DJ. Which depressive symptoms are related to which sleep electroencephalographic variables? Biol Psychiatry. 1997;42(10):904-913.

93. Cartwright RD. Rapid eye movement sleep characteristics during and after mood-disturbing events. Arch Gen Psychiatry. 1983;40(2): 197-201.

94. Buysse DJ, Frank E, Lowe KK, Cherry CR, Kupfer DJ. Electroencephalographic sleep correlates of episode and vulnerability to recurrence in depression. Biol Psychiatry. 1997;41(4):406-418.

95. Nofzinger EA, Schwartz RM, Reynolds CF 3rd, et al. Affect intensity and phasic REM sleep in depressed men before and after treatment with cognitive-behavioral therapy. J Consult Clin Psychol. 1994;62(1):83-91.

96. Thase ME, Fasiczka AL, Berman SR, Simons AD, Reynolds CF 3rd. Electroencephalographic sleep profiles before and after cognitive behavior therapy of depression. Arch Gen Psychiatry. 1998;55(2): 138-144.

97. Rush AJ, Erman MK, Giles DE, et al. Polysomnographic findings in recently drug-free and clinically remitted depressed patients. Arch Gen Psychiatry. 1986;43(9):878-884.

98. Lauer CJ, Schreiber W, Holsboer F, Krieg JC. In quest of identifying vulnerability markers for psychiatric disorders by all-night polysomnography. Arch Gen Psychiatry. 1995;52(2):145-153.

99. Nofzinger EA, Thase ME, Reynolds CF 3rd, et al. Hypersomnia in bipolar depression: a comparison with narcolepsy using the multiple sleep latency test. Am J Psychiatry. 1991;148(9):1177-1181.

100. Billiard M, Dolenc L, Aldaz C, Ondze B, Besset A. Hypersomnia associated with mood disorders: a new perspective. J Psychosom Res. 1994;38 Suppl 1:41-47.

101. Anderson JL, Rosen LN, Mendelson WB, et al. Sleep in fall/winter seasonal affective disorder: effects of light and changing seasons. J Psychosomatic Res. 1994;38(4):323-337.

102. Dallaspezia S, Benedetti F. Chronobiological therapy for mood disorders. Expert Rev Neurother. 2011;11(7):961-970.

103. Vogel GW, Thurmond A, Gibbons P, Sloan K, Walker M. REM sleep reduction effects on depression syndromes. Arch Gen Psychiatry. 1975;32(6):765-777. 
104. Wiegand MH, Lauer CJ, Schreiber W. Patterns of Response to repeated total sleep deprivations in depression. J Affective Disorders. 2001 May;64(2-3):257-260.

105. Sandor P, Shapiro CM. Sleep patterns in depression and anxiety: theory and pharmacological effects. J Psychosom Res. 1994;38 Suppl 1: 125-139.

106. Partonen T, Lönnqvist J. Seasonal affective disorder. Lancet. 1998;352(9137):1369-1374.

107. Sharpley AL, Cowen PJ. Effect of pharmacologic treatments on the sleep of depressed patients. Biol Psychiatry. 1995;37(2):85-98.

108. Wilson S, Argyropoulos S. Antidepressants and sleep: a qualitative review of the literature. Drugs. 2005;65(7):927-947.

109. Herbert J. Cortisol and depression: three questions for psychiatry. Psychol Med. 2013;43(3):449-469.

110. Li SX, Lam SP, Chan JW, Yu MW, Wing YK. Residual sleep disturbances in patients remitted from major depressive disorder: a 4-year naturalistic follow-up study. Sleep. 2012;35(8):1153-1161.

111. Martiny K, Refsgaard E, Lund V, et al. A 9-week randomized trial comparing a chronotherapeutic intervention (wake and light therapy) to exercise in major depressive disorder patients treated with duloxetine. J Clin Psychiatry. 2012;73(9):1234-1242.

112. Harvey AG, Schmidt DA, Scarnà A, Semler CN, Goodwin GM. Sleeprelated functioning in euthymic patients with bipolar disorder, patients with insomnia, and subjects without sleep problems. Am J Psychiatry 2005;162(1):50-57.

113. Murray G, Harvey A. Circadian rhythms and sleep in bipolar disorder. Bipolar Disord. 2010;12(5):459-472.

114. Harvey AG. Sleep and circadian functioning: critical mechanisms in the mood disorders? Annu Rev Clin Psychol. 2011;7:297-319.

115. Stoleru S, Nottelmann ED, Belmont B, Ronsaville D. Sleep problems in children of affectively ill mothers. J Child Psychol Psychiatry. 1997;38(7):831-841.

116. Shaw JA, Egeland JA, Endicott J, Allen CR, Hostetter AM. A 10-year prospective study of prodromal patterns for bipolar disorder among Amish youth. J Am Acad Child Adolesc Psychiatry. 2005;44(11): 1104-1111.

117. Jones SH, Tai S, Evershed K, Knowles R, Bentall R. Early detection of bipolar disorder: a pilot familial high-risk study of parents with bipolar disorder and their adolescent children. Bipolar Disord 2006;8(4):362-372.

118. Ankers D, Jones SH. Objective assessment of circadian activity and sleep patterns in individuals at behavioural risk of hypomania. J Clin Psychol. 2009;65(10):1071-1086.

119. Ritter PS, Marx C, Lewtschenko N, et al. The characteristics of sleep in patients with manifest bipolar disorder, subjects at high risk of developing the disease and healthy controls. J Neural Transm. 2012;119(10):1173-1184.

120. Skjelstad DV, Malt UF, Holte A. Symptoms and signs of the initial prodrome of bipolar disorder: a systematic review. J Affect Disord 2010;126(1-2):1-13.

121. Ritter PS, Marx C, Bauer M, Leopold K, Pfennig A. The role of disturbed sleep in the early recognition of bipolar disorder: a systematic review. Bipolar Disord. 2011;13(3):227-237.

122. Jackson A, Cavanagh J, Scott J. A systematic review of manic and depressive prodromes. J Affect Disord. 2003;74(3):209-217.

123. Wehr TA, Sack DA, Rosenthal NE. Sleep reduction as a final common pathway in the genesis of mania. Am J Psychiatry. 1987;144(2):201-204.

124. Plante DT, Winkelman JW. Sleep disturbance in bipolar disorder: therapeutic implications. Am J Pscyhiatry. 2008;165(7):830-843.

125. Colombo C, Benedetti F, Barbini B, Campori E, Smeraldi E. Rate of switch from depression into mania after therapeutic sleep deprivation in bipolar depression. Psychiatry Res. 1999;86(3): 267-270.

126. Harvey AG. Sleep and circadian rhythms in bipolar disorder: seeking synchrony, harmony, and regulation. Am J Psychiatry. 2008;165(7):820-829.
127. Hudson JI, Lipinski JF, Frankenburg FR, Grochocinski VJ, Kupfer DJ. Electroencephalographic sleep in mania. Arch Gen Psychiatry. 1988;45(3):267-273.

128. Linkowski P, Mendlewicz J. Sleep electroencephalogram and rhythm disturbances in mood disorders. Curr Opin Psychiatr. 1993; 6(1):35-37.

129. Hudson JI, Lipinski JF, Keck PE Jr, et al. Polysomnographic characteristics of young manic patients. Comparison with unipolar depressed patients and normal control subjects. Arch Gen Psychiatry. 1992;49(5):378-383.

130. Gillin JC, Duncan W, Pettigrew KD, Frankel BL, Snyder F. Successful separation of depressed, normal, and insomniac subjects by EEG sleep data. Arch Gen Psychiatry. 1979;36(1):85-90.

131. Jernajczyk W. Latency of eye movement and other REM sleep parameters in bipolar depression. Biol Psychiatry. 1986;21(5-6):465-472.

132. Lauer CJ, Wiegand M, Krieg JC. All-night electroencephalographic sleep and cranial computed tomography in depression. A study of unipolar and bipolar patients. Eur Arch Psychiatry Clin Neurosci. 1992;242(2-3):59-68.

133. Thase ME, Himmelhoch JM, Mallinger AG, Jarrett DB, Kupfer DJ. Sleep EEG and DST findings in anergic bipolar depression. Am J Psychiatry. 1989;146(3):329-333.

134. Sitaram N, Nurnberger JI Jr, Gershon ES, Gillin JC. Cholinergic regulation of mood and REM sleep: potential model and marker of vulnerability to affective disorder. Am J Psychiatry. 1982;139(5):571-576.

135. Eidelman P, Talbot LS, Gruber J, Harvey AG. Sleep, illness course, and concurrent symptoms in inter-episode bipolar disorder. J Behav Ther Exp Psychiatry. 2010;41(2):145-149.

136. Knowles JB, Cairns J, MacLean AW, et al. The sleep of remitted bipolar depressives: comparison with sex and age-matched controls. Can J Psychiatry. 1986;31(4):295-298.

137. St-Amand J, Provencher MD, Belanger L, Morin CM. Sleep disturbances in bipolar disorder during remission. J Affect Disord. Epub August 9, 2012.

138. Kaplan KA, Gruber J, Eidelman P, Talbot LS, Harvey AG. Hypersomnia in inter-episode bipolar disorder: does it have prognostic significance? J Affect Disord. 2011;132(3):438-444.

139. Eidelman P, Talbot LS, Gruber J, Hairston I, Harvey AG. Sleep architecture as correlate and predictor of symptoms and impairment in inter-episode bipolar disorder: taking on the challenge of medication effects. J Sleep Res. 2010;19(4):516-524.

140. Millar A, Espie CA, Scott J. The sleep of remitted bipolar outpatients: a controlled naturalistic study using actigraphy. $J$ Affect Disord. 2004;80(2-3):145-153.

141. Jones SH, Hare DJ, Evershed K. Actigraphic assessment of circadian activity and sleep patterns in bipolar disorder. Bipolar Disord. 2005;7(2):176-186.

142. Etain B, Milhiet V, Bellivier F, Leboyer M. Genetics of circadian rhythms and mood spectrum disorders. Eur Neuropsychopharmacol. 2011;21 Supp1 4:S676-S682.

143. Mansour HA, Wood J, Chowdari KV, et al. Circadian phase variation in bipolar I disorder. Chronobiol Int. 2005;22(3):571-584.

144. Ahn YM, Chang J, Joo YH, Kim SC, Lee KY, Kim YS. Chronotype distribution in bipolar I disorder and schizophrenia in a Korean sample. Bipolar Disord. 2008;10(2):271-275.

145. Wood J, Birmaher B, Axelson D, et al. Replicable differences in preferred circadian phase between bipolar disorder patients and control individuals. Psychiatry Res. 2009;166(2-3):201-209.

146. Giglio LM, Magalhães PV, Andersen ML, Walz JC, Jakobson L, Kapczinski F. Circadian preference in bipolar disorder. Sleep Breath. 2010;14(2):153-155.

147. Salvatore P, Ghidini S, Zita G, et al. Circadian activity rhythm abnormalities in ill and recovered bipolar I disorder patients. Bipolar Disord. 2008;10(2):256-265.

148. Shen GH, Alloy LB, Abramson LY, Sylvia LG. Social rhythm regularity and the onset of affective episodes in bipolar spectrum individuals. Bipolar Disord. 2008;10(4):520-529. 
149. Lewy AJ, Wehr TA, Goodwin FK, Newsome DA, Rosenthal NE. Manic-depressive patients may be supersensitive to light. Lancet. 1981;1(8216):383-384.

150. Lewy AJ, Nurnberger JI Jr, Wehr TA, et al. Supersensitivity to light: possible trait marker for manic-depressive illness. Am J Psychiatry. 1985;142(6):725-727.

151. Nathan PJ, Burrows GD, Norman TR. Melatonin sensitivity to dim white light in affective disorders. Neuropsychopharmacology. 1999;21(3):408-413.

152. Whalley LJ, Perini T, Shering A, Bennie J. Melatonin response to bright light in recovered, drug-free, bipolar patients. Psychiatry Res. 1991;38(1):13-19.

153. Lam RW, Berkowitz AL, Berga SL, Clark CM, Kripke DF, Gillin JC. Melatonin suppression in bipolar and unipolar mood disorders. Psychiatry Res. 1990;33(2):129-134.

154. Nurnberger JI Jr, Adkins S, Lahiri DK, et al. Melatonin suppression by light in euthymic bipolar and unipolar patients. Arch Gen Psychiatry. 2000;57(6):572-579.

155. Etain B, Dumaine A, Bellivier F, et al. Genetic and functional abnormalities of the melatonin biosynthesis pathway in patients with bipolar disorder. Human Mol Gen. 2012;21(18):4030-4037.

156. Norris ER, Karen B, Correll JR, et al. A double-blind, randomized, placebo-controlled trial of adjunctive ramelteon for the treatment of insomnia and mood stability in patients with euthymic bipolar disorder. $J$ Affect Disord. 2013;144(1-2):141-147.

157. Calabrese JR, Guelfi JD, Perdrizet-Chevallier C; Agomelatine Bipolar Study Group. Agomelatine adjunctive therapy for acute bipolar depression: preliminary open data. Bipolar Disord. 2007;9(6): 628-635.

158. Dallaspezia S, Benedetti F. Chronobiological therapy for mood disorders. Expert Rev Neurother. 2011;11(7):961-970.

159. Wu JC, Kelsoe JR, Schachat C, et al. Rapid and sustained antidepressant response with sleep deprivation and chronotherapy in bipolar disorder. Biol Psychiatry. 2009;66(3):298-301.

160. Frank E, Kupfer DJ, Thase ME, et al. Two-year outcomes for interpersonal and social rhythm therapy in individuals with bipolar I disorder. Arch Gen Psychiatry. 2005;62(9):996-1004.

161. Miklowitz DJ, Otto MW, Frank E, et al. Psychosocial treatments for bipolar depression: a 1-year randomized trial from the Systematic Treatment Enhancement Program. Arch Gen Psychiatry. 2007;64(4):419-426.

162. Maina G, Salvi V, Vitalucci A, D’Ambrosio V, Bogetto F. Prevalence and correlates of overweight in drug-naïve patients with bipolar disorder. J Affect Disord. 2008;110(1-2):149-155.

163. Taylor V, Macdonald K, McKinnon MC, Joffe RT, MacQueen GM. Increased rates of obesity in first-presentation adults with mood disorders over the course of four-year follow-up. J Affect Disord. 2008;109(1-2):127-131.

164. Bliwise DL. Normal aging. In: Kryger MH, Roth T, Dement WC, editors. Principals and Practice of Sleep Medicine. Philadelphia, PA: Elsevier Sanders; 2005:24-38.

165. Ancoli-Israel S. Sleep and aging: prevalence of disturbed sleep and treatment considerations in older adults. J Clin Psychiatry. 2005;66 Suppl 9:24-30; quiz 42-23.

166. Foley DJ, Monjan AA, Brown SL, Simonsick EM, Wallace RB, Blazer DG. Sleep complaints among elderly persons: an epidemiologic study of three communities. Sleep. 1995;18(6):425-432.

167. Cooke JR, Liu L, Natarajan L, et al. The effect of sleep-disordered breathing on stages of sleep in patients with Alzheimer's disease. Behav Sleep Med. 2006;4(4):219-227.

168. Ancoli-Israel S, Ayalon L, Salzman C. Sleep in the elderly: normal variations and common sleep disorders. Harv Rev Psychiatry. 2008;16(5):279-286.

169. Cooke JR, Ancoli-Israel S, Liu L, et al. Continuous positive airway pressure deepens sleep in patients with Alzheimer's disease and obstructive sleep apnea. Sleep Med. 2009;10(10):1101-1106.
170. Moraes W, Poyares D, Sukys-Claudino L, Guilleminault C, Tufik S. Donepezil improves obstructive sleep apnea in Alzheimer disease: a double-blind, placebo-controlled study. Chest. 2008;133(3): 677-683.

171. Ancoli-Israel S, Kripke DF, Klauber MR, Mason WJ, Fell R, Kaplan O. Periodic limb movements in sleep in community-dwelling elderly. Sleep. 1991;14(6):496-500.

172. Foley D, Ancoli-Israel S, Britz P, Walsh J. Sleep disturbances and chronic disease in older adults: results of the 2003 National Sleep Foundation Sleep in America Survey. J Psychosom Res. 2004;56(5): 497-502.

173. Mazzoccoli G, Vendemiale G, La Viola M, et al. Circadian variations of cortisol, melatonin and lymphocyte subpopulations in geriatric age. Int J Immunopathol Pharmacol. 2010;23(1): 289-296.

174. Lieberman HR, Wurtman JJ, Teicher MH. Circadian rhythms of activity in healthy young and elderly humans. Neurobiol Aging. 1989;10(3):259-265.

175. Monk TH, Buysse DJ, Billy BD, et al. Circadian type and bed-timing regularity in 654 retired seniors: correlations with subjective sleep measures. Sleep. 2011;34(2):235-239.

176. Schmidt C, Peigneux P, Cajochen C. Age-related changes in sleep and circadian rhythms: impact on cognitive performance and underlying neuroanatomical networks. Front Neurol. 2012;3:118

177. Thomas P, Chantoin-Merlet S, Hazif-Thomas C, et al. Complaints of informal caregivers providing home care for dementia patients: the Pixel study. Int J Geriatr Psychiatry. 2002;17(11):1034-1047.

178. Hatfield CF, Herbert J, van Someren EJ, Hodges JR, Hastings MH. Disrupted daily activity/rest cycles in relation to daily cortisol rhythms of home-dwelling patients with early Alzheimer's dementia. Brain. 2004;127(Pt 5):1061-1074.

179. Van Someren EJ. Actigraphic monitoring of movement and rest-activity rhythms in aging, Alzheimer's disease, and Parkinson's disease. IEEE Trans Rehabil Eng. 1997;5(4):394-398.

180. Most EI, Aboudan S, Scheltens P, Van Someren EJ. Discrepancy between subjective and objective sleep disturbances in early- and moderate-stage Alzheimer disease. Am J Geriatr Psychiatry. 2012;20(6):460-467.

181. Dowling GA, Burr RL, Van Someren EJ, et al. Melatonin and bright-light treatment for rest-activity disruption in institutionalized patients with Alzheimer's disease. J Am Geriatr Soc. 2008;56(2): 239-246.

182. Gehrman PR, Connor DJ, Martin JL, Shochat T, Corey-Bloom J, Ancoli-Israel S. Melatonin fails to improve sleep or agitation in double-blind randomized placebo-controlled trial of institutionalized patients with Alzheimer disease. Am J Geriatr Psychiatry. 2009;17(2): 166-169

183. Bliwise DL, Tinklenberg J, Yesavage JA, et al. REM latency in Alzheimer's disease. Biol Psychiatry. 1989;25(3):320-328.

184. Loewenstein RJ, Weingartner H, Gillin JC, Kaye W, Ebert M, Mendelson WB. Disturbances of sleep and cognitive functioning in patients with dementia. Neuro Aging. 1982;3(4):371-377.

185. Reynolds CF 3rd, Kupfer DJ, Taska LS, Hoch CH, Sewitch DE, Grochocinski VJ. Slow wave sleep in elderly depressed, demented, and healthy subjects. Sleep. 1985;8(2):155-159.

186. Vitiello MV, Prinz PN. Alzheimer's disease. Sleep and sleep/wake patterns. Clin Geriatr Med. 1989;5(2):289-299.

187. Yesavage JA, Friedman L, Kraemer H, et al. Sleep/wake disruption in Alzheimer's disease: APOE status and longitudinal course. J Geriatr Psychiatry Neurol. 2004;17(1):20-24.

188. Rauchs G, Schabus M, Parapatics S, et al. Is there a link between sleep changes and memory in Alzheimer's disease? Neuroreport. 2008;19(11):1159-1162.

189. Gagnon JF, Petit D, Fantini ML, et al. REM sleep behavior disorder and REM sleep without atonia in probable Alzheimer disease. Sleep. 2006;29(10):1321-1325. 
190. Parkinson J. An Essay on the Shaking Palsy. Sherwood, Nealy and Jones, editors. London: Whittingham and Rowland; 1817.

191. Yong MH, Fook-Chong S, Pavanni R, Lim LL, Tan EK. Case control polysomnographic studies of sleep disorders in Parkinson's disease. PloS One. 2011;6(7):e22511.

192. Khedr EM, El Fetoh NA, Khalifa H, Ahmed MA, El Beh KM. Prevalence of non motor features in a cohort of Parkinson's disease patients. Clin Neurol Neurosurg. Epub August 16, 2012.

193. Iranzo A. Sleep-wake changes in the premotor stage of Parkinson disease. J Neurol Sci. 2011;310(1-2):283-285.

194. Boeve BF. REM sleep behavior disorder: Updated review of the core features, the REM sleep behavior disorder-neurodegenerative disease association, evolving concepts, controversies, and future directions. Ann NY Acad Sci. 2010;1184:15-54.

195. Arnulf I. REM sleep behavior disorder: motor manifestations and pathophysiology. Mov Disord. 2012;27(6):677-689.

196. Fulda S. Idiopathic REM sleep behavior disorder as a long-term predictor of neurodegenerative disorders. EPMA J. 2011;2(4):451-458.

197. Nomura T, Inoue $Y$, Kagimura T, Nakashima K. Clinical significance of REM sleep behavior disorder in Parkinson's disease. Sleep Med. 2013;14(2):131-135.

198. Claassen DO, Josephs KA, Ahlskog JE, Silber MH, Tippmann-Peikert M, Boeve BF. REM sleep behavior disorder preceding other aspects of synucleinopathies by up to half a century. Neurology. 2010;75(6):494-499.

199. Ferini-Strambi L, Marelli S. Sleep dysfunction in multiple system atrophy. Curr Treat Options Neurol. 2012;14(5):464-473.

200. Nomura T, Inoue Y, Takigawa H, Nakashima K. Comparison of REM sleep behaviour disorder variables between patients with progressive supranuclear palsy and those with Parkinson's disease. Parkinsonism Relat Disord. 2012;18(4):394-396.

201. Postuma RB, Bertrand JA, Montplaisir J, et al. Rapid eye movement sleep behavior disorder and risk of dementia in Parkinson's disease: a prospective study. Mov Disord. 2012;27(6):720-726.

202. Chaudhuri KR, Pal S, Brefel-Courbon C. 'Sleep attacks' or 'unintended sleep episodes' occur with dopamine agonists: is this a class effect? Drug Saf. 2002;25(7):473-483.

203. Ferreira JJ, Desboeuf K, Galitzky M, et al. Sleep disruption, daytime somnolence and 'sleep attacks' in Parkinson's disease: a clinical survey in PD patients and age-matched healthy volunteers. Eur J Neurol. 2006;13(3):209-214.

204. Arnulf I, Leu S, Oudiette D. Abnormal sleep and sleepiness in Parkinson's disease. Curr Opin Neurol. 2008;21(4):472-477.

205. Uc EY, Rizzo M, Johnson AM, Dastrup E, Anderson SW, Dawson JD. Road safety in drivers with Parkinson disease. Neurology. 2009;73(24): 2112-2119.

206. Crizzle AM, Classen S, Uc EY. Parkinson disease and driving: An evidence-based review. Neurology. 2012;79(20):2067-2074.
207. Bliwise DL, Mercaldo ND, Avidan AY, Boeve BF, Greer SA, Kukull WA. Sleep disturbance in dementia with Lewy bodies and Alzheimer's disease: a multicenter analysis. Dement Geriatr Cogn Disord. 2011;31(3):239-246.

208. Ferman TJ, Boeve BF, Smith GE, et al. Dementia with Lewy bodies may present as dementia and REM sleep behavior disorder without parkinsonism or hallucinations. J Int Neuropsychol Soc. 2002;8(7): 907-914.

209. Ferman TJ, Boeve BF, Smith GE, et al. Inclusion of RBD improves the diagnostic classification of dementia with Lewy bodies. Neurology. 2011;77(9):875-882.

210. Dugger BN, Boeve BF, Murray ME, et al. Rapid eye movement sleep behavior disorder and subtypes in autopsy-confirmed dementia with Lewy bodies. Mov Disord. 2012;27(1):72-78.

211. Guarnieri B, Adorni F, Musicco M, et al. Prevalence of sleep disturbances in mild cognitive impairment and dementing disorders: a multicenter Italian clinical cross-sectional study on 431 patients. Dement Geriatr Cogn Disord. 2012;33(1):50-58.

212. Anderson KN, Hatfield C, Kipps C, Hastings M, Hodges JR. Disrupted sleep and circadian patterns in frontotemporal dementia. Eur J Neurol. 2009;16(3):317-323.

213. Merrilees J, Hubbard E, Mastick J, Miller BL, Dowling GA Rest-activity and behavioral disruption in a patient with frontotemporal dementia. Neurocase. 2009;15(6):515-526.

214. Taylor N, Bramble D. Sleep disturbance and Huntingdon's disease. $\mathrm{Br}$ J Psychiatry. 1997;171:393.

215. Videnovic A, Leurgans S, Fan W, Jaglin J, Shannon KM. Daytime somnolence and nocturnal sleep disturbances in Huntington disease. Parkinsonism Relat Disord. 2009;15(6):471-474.

216. Emser W, Brenner M, Stober T, Schimrigk K. Changes in nocturnal sleep in Huntington's and Parkinson's disease. J Neurol. 1988;235(3): 177-179.

217. Aziz NA, Anguelova GV, Marinus J, Lammers GJ, Roos RA. Sleep and circadian rhythm alterations correlate with depression and cognitive impairment in Huntington's disease. Parkinsonism Relat Disord. 2010;16(5):345-350.

218. Björkqvist M, Petersén A, Nielsen J, et al. Cerebrospinal fluid levels of orexin-A are not a clinically useful biomarker for Huntington disease. Clin Genet. 2006;70(1):78-79.

219. Gaus SE, Lin L, Mignot E. CSF hypocretin levels are normal in Huntington's disease patients. Sleep. 2005;28(12):1607-1608.

220. Goodman AO, Rogers L, Pilsworth S, et al. Asymptomatic sleep abnormalities are a common early feature in patients with Huntington's disease. Curr Neurol Neurosci Rep. 2011;11(2):211-217.

221. Beersma DG, Gordijn MC. Circadian control of the sleep-wake cycle. Physiol Behav. 2007;90(2-3):190-195.
Nature and Science of Sleep

\section{Publish your work in this journal}

Nature and Science of Sleep is an international, peer-reviewed, open access journal covering all aspects of sleep science and sleep medicine, including the neurophysiology and functions of sleep, the genetics of sleep, sleep and society, biological rhythms, dreaming, sleep disorders and therapy, and strategies to optimize healthy sleep. The journal welcomes

\section{Dovepress}

original research, clinical \& epidemiological studies, reviews \& evaluations, case reports and extended reports. The manuscript management system is completely online and includes a very quick and fair peerreview system, which is all easy to use. Visit http://www.dovepress.com/ testimonials.php to read real quotes from published authors. 